\title{
EXTREMUM SEEKING BASED FAULT ESTIMATION FOR OUTPUT FEEDBACK CONTROL OF FLEXIBLE-JOINT ROBOT MANIPULATOR
}

\author{
Selami BEYHAN \\ İzmir Democracy University, Electrical and Electronics Engineering, Uckuyular Dist., 35140 Karabaglar, İzmir, \\ TÜRKIYE \\ selami.beyhan@idu.edu.tr
}

(Geliş/Received: 30.06.2020; Kabul/Accepted in Revised Form: 09.02.2021)

\begin{abstract}
In this paper, an extremum seeking fault estimation based output feedback controller is proposed for the control of flexible-joint robot manipulator. First, using the approximate nonlinear robot model, a extremum seeking controller is designed to minimize the tracking error via output feedback. Then, in order to prevent the effects of faults, disturbances or unknown dynamics, an extremum seeking based fault estimator is proposed. In order to show that the advantage of the proposed configuration, a flexible-joint manipulator with unknown fault is controlled both in a numerical simulation and real-time experiment. An artificial payload is applied to the end-effector in a simulation environment. But, in the real-time experiment, an additional payload attached to the end effector when it is continuing the process. The approximate model of the robot manipulator is obtained by the state-space identification. As a result using the proposed estimation and controller, acceptable tracking and estimation results are obtained both in numerical and real-time experiments for future applications.
\end{abstract}

Key Words: Extremum seeking optimization, output feedback control, fault estimation and tolerance, flexible-joint manipulator, varying payload, stability.

\section{Ekstremum Arama Temelli Hata Tahmini ile Esnek Bağlantılı Robot Kolunun Çıkış Geri Besleme Kontrolü}

ÖZ: Bu çalışmada, ekstremum arama hata tahmini ve ekstremum arama temelli çıkış geri besleme kontrolcüsü doğrusal olmayan esnek-bağlantılı robot kolu için önerilmiştir. İlk olarak, doğrusal olmayan sistemin yaklaşık modeli kullanılarak izleme hatasını minimize etmek için çıkış geribesleme ile ekstremum arama denetleyicisi tasarlanmıştır. Daha sonra hataların, bozucu etkilerin ve bilinmeyen dinamiklerin etkisini yok etmek için ekstremum arama hata tahminleyicisi tasarlanmıştır. Önerilen hata tahminleyici temelli kontrolün avantajını göstermek için bilinmeyen yüke sahip esnek-bağlantılı robot kolu benzetim ortamında ve gerçek zamanlı olarak kontrol edilmiştir. Benzetim ortamında yapay bir yük uygulanmıştır. Fakat gerçek-zamanlı deneyde, esnek bağlantılı robot kolu çalışmaya devam ederken üzerine ek yük bağlanmıştır. Esnek-bağlantılı robot kolunun yaklaşık modeli ise durum uzayı tanılama ile elde edilmiştir. Sonuç olarak önerilen tahminleyici ve kontrolör yöntemi ile gelecek uygulamalar içinde kabul edilebilir izleme ve tahmin sonuçları hem benzetim ortamında hem de gerçek-zamanlı deneylerde elde edilmiştir.

Anahtar Kelimeler: Ekstremum arama metodu, çıkış geribesleme kontrol, hata tahmini ve toleransı, esnek bağlantılı robot kolu, değişken yük ve kararllık. 


\section{INTRODUCTION}

Industrial systems have always unmodeled dynamics, disturbances or time-varying parameters. Therefore, in order to get accurate performances of the real-time control, suitable controller design must be selected. The effect of the unmodeled dynamics might be compensated with robust controllers when the approximate model of the system is known. However, if there is no available mathematical model of the system; adaptive control, identification-based control or some classical control methods can be designed (Astrom et al. 1994, Spooner et al. 2002). Some of these control methods have fault tolerant behavior due to the compensation of integrative error, so that small magnitude of unknown dynamics can be compensated. On the other hand, when the system fault is large, an auxiliary estimator and controller are to be designed for the accurate tracking (Noura et al. 2009).

Extremum seeking control (ESC) is a real-time constrained optimization-based control approach (Krstic et al 2000, Ariyur et al. 2003, Dochain et al. 2011). Fundamentally, extremum seeking scheme optimizes a cost function by calculating the second-order gradient information with respect to its parameter. For the feedback control design, the cost function is a tracking error or a function of the system output, then the optimizing parameter is the control signal of the system. ESC does not use the mathematical model of the system therefore it has been recently much attention for the control applications. Even though the extremum seeking controller is referred as one of the" early methods" (Ariyur et al. 2003, Dochain et al. 2011), its local and semi-global stability are proved by (Krstic et al 2000, Tan et al. 2009). Some of the industrial applications are (Guay et al. 2004, Dower et al. 2008, Brunton et al. 2010). After the stability of the extremum seeking controller is proved, there have been various control designs and many applications. Especially, switching or sliding-mode based extremum seeking controller (Pan et al. 2003, Oliveira et al. 2012, Chen et al. 2017), extremum seeking model predictive controller (Subbaraman et al. 2016), extremum seeking based PID tuning (Killingworth et al. 2006), multi-objective extremum seeking controller (Zhang et al. 2007, Guay et al. 2015, Ye at al. 2016), extremum seeking-like observer (Sassano et al. 2011) are known applications. In addition, stochastic extremum seeking optimization is introduced where its maximization/minimization performance is proved to be better than deterministic extremum seeking optimization (Liu et al. 2012). In order to improve the steady state-error and local performance of the extremum seeking control, modified versions are proposed in (Hazeleger et al. 2020, Zhao et al. 2020), respectively.

Based on the literature studies, the improvements on the performance of the extremum seeking control are mainly based on the assistance of the conventional methods and optimization-based parameter tuning. In this paper, to increase the tracking efficiency of the conventional extremum seeking controller, an adaptive extremum seeking based fault estimation and extremum seeking based fault tolerant controller are designed for linear and nonlinear systems with process faults. The estimated fault is forced as an additional input to the system to be compensated. In application part, the proposed fault tolerant controller design is applied to an experimental flexible joint manipulator with varying payloads. Both in numerical simulations and real-time applications, acceptable tracking and estimation results are provided for further applications. The sole extremum seeking controller and extremum seeking fault tolerant controller are numerically compared in root-mean squared tracking error (RMSE) sense under varying payload case.

\section{EXTREMUM SEEKING OPTIMIZATION}

Extremum seeking optimization scheme (Krstic et al 2000, Dochain et al. 2011) is shown in Figure 1 to optimize output cost function y. The theory behind the extremum seeking is given as follows. The cost function of the system is first passed from the wash-out filter which is a high-pass filter. Then, the filtered signal is modulated with a high- frequency sine signal. After that, the modulated signal is passed from a low pass filter. Finally, the parameter change is integrated and summed by the modulating signal then an optimized parameter is obtained. The resulting signal is a second-order gradient of the cost function with respect to its parameters. 
Consider a single-input single-output (SISO) nonlinear state space system is

$$
\begin{aligned}
& x=f(x, u), \\
& y=g(x),
\end{aligned}
$$

where $x(t) \in R^{n}$ is state vector, $u(t) \in R$ is input and $y(t) \in R$ is output of the system. A smooth control signal $u=\alpha(x, \theta)$ is defined with an adaptable parameter, then the closed-system dynamics,

$$
\dot{x}=f(x, \alpha(x, \theta))
$$

has an equilibrium with the parameter $\theta$. The following assumptions can be made for the closed-loop system.

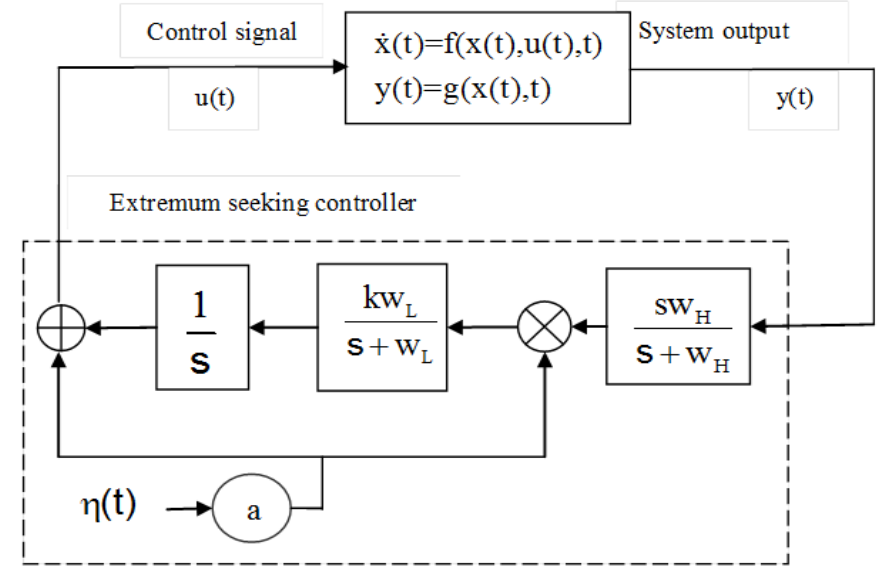

Figure 1. Extremum seeking controller scheme.

Assumption 1. There exists a smooth function $\boldsymbol{h}: R \rightarrow R^{n}$ such that

$$
f(x, \alpha(x, \theta))=0 \text {, if and only if } x=\boldsymbol{h}(\theta)
$$

Assumption 2. For each $\theta \in R$ the equilibrium $x=\boldsymbol{h}(\theta)$ of the system (3) is locally exponentially stable.

Assumption 3. There exists a $\theta^{*} \in R$ such that $(g \circ h)^{\prime}\left(\theta^{*}\right)=0$

$$
(g \circ h)^{\prime \prime}\left(\theta^{*}\right)<0
$$

Based on three assumptions and the feedback design seen in Figure 1, it is proved that $y=g(x)$ function has a maximum at $\theta=\theta^{*}$. Its stability analysis and convergence of control signal are shown (Pan et al. 2003). To get the minimum of y output cost function, it is replaced by $-y$. Using the extremum seeking control, the change of the parameter (Ariyur et al. 2003) is derived as

$$
\dot{\hat{\theta}}=-k a \frac{1}{2} \frac{\partial^{2} y}{\partial \widehat{\theta}^{2}} \hat{\theta}
$$

where the by choosing the suitable parameters of the extremum seeking optimization, the parameter update can be obtained in real-time. In literature, nonlinear uncertain systems with disturbances are controlled with extremum seeking control. In (Dochain et al. 2011), an extended state observer-based regulator is designed, and conjugate gradient based extremum seeking is achieved. In (Lara et al. 2017), extremum seeking sliding-mode controller is designed for input-output linearized model with an uncertainty function.

\section{STOCHASTIC EXTREMUM SEEKING FAULT TOLERANT CONTROL}

In this paper, an extremum seeking optimization-based fault estimator and compensator is proposed. In fault estimation step, an approximate model of the system is utilized as a reference model. Then, the output estimation error is defined as $\hat{e}=\hat{y}-y$ where $\hat{y}$ is the output of the reference model and $y$ is the output of the real system. The output estimation error is minimized by an extremum seeking optimization such that the discrepancy between the system output and approximate model output is considered as the 
fault of the system dynamics. In fault compensation step, the produced output of the extremum seeking estimator will be the fault variable which is used as an additional input function to minimize the estimation error of the system. The ideas for the construction of the approximate model are given above.

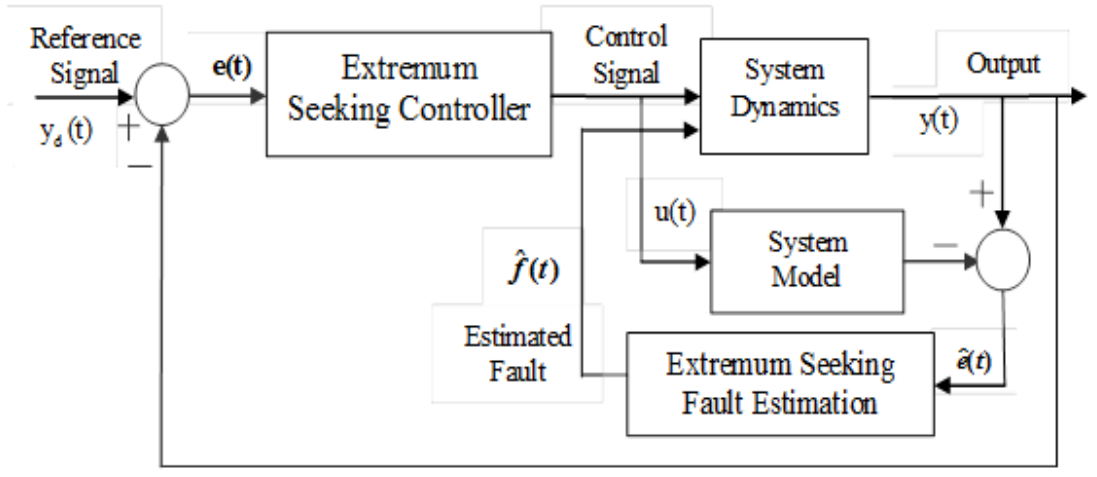

Figure 2. Fault tolerant controller scheme.

The proposed fault tolerant controller optimizes simultaneously the tracking error $e=y_{d}-y$ with respect to control parameter and the estimation error $\hat{e}=\hat{y}-y$ with respect to fault variable where $\hat{y}$ is the approximate output of the system and $y_{d}$ is the reference signal. It is assumed that $\hat{y}$ is here a fault free output of the system. Like the control parameter update (5), the adaptive fault estimation is defined as

$$
\dot{\hat{f}}(t)=-\alpha \beta \frac{1}{2} \frac{\partial^{2} \hat{e}}{\partial \hat{f}^{2}} \hat{f}
$$

where $\alpha$ and $\beta$ are design parameters. Note that the produced control signal and fault variable are applied to the system dynamics then the resulting output signal is obtained. Therefore, the optimized parameter must satisfy the system dynamics, which presents a constrained optimization. The proposed control scheme is shown in Figure 2.

\section{APPROXIMATE MODELING OF FLEXIBLE-JOINT MANIPULATOR}

The flexible joint manipulator consists of double integrator, but it has single input single output dynamics. The input is a control voltage applied to the first motor; the output is the angle position of the end-effector. Due to the spring behavior, it is difficult to position of the end effector when large payloads are loaded. It is produced by Quanser Inc. and compatible with MATLAB/SIMULINK environments. Therefore, it is a suitable system to test the designed observers and controllers. The flexible-joint manipulator is shown in Figure 3. Its mathematical dynamics has been already derived using Lagrange equations (Groves et al. 2004) such that its dynamics have weak nonlinear sine term. Therefore, the experimental set up is supplied by the manufacturer with a linearized model and an observer design (Quanser, 2012) of velocity estimations. In literature, observer and tip position measurement-based methods also exist (Talole et al. 2010, Beyhan 2016, Agee et al. 2014) to get accurate tracking results. In this study, for the purpose of extremum seeking based design, its physical model will not be used. The input voltage and output tip position are available to get an approximate model.

For the sake of simplicity, the approximate model of the system may be constructed in three ways. If the mathematical model of the physical system exists, then it can be used as an approximate model since the real-time working system has always different dynamics than known mathematical model.

- If there is no physical model and the input-output measurements are available, then the inputoutput data must be analyzed for appropriate model selection. If the system dynamics are linear or have mild nonlinear terms then using linear or nonlinear state-space subspace identification methods, a state space model can be constructed with optimization methods. 
- Addition to the second item, if the system dynamics have time-delay, nonminimum phase dynamics or strong nonlinearities, then support-vector machine, neural-network, fuzzy system, orthogonal function networks and etc. can be used to model the system in appropriate forms.

The approximate model of the system is here modeled via a linear state-space model. It is constructed by a $4 t h$-order model since it has double integrator of two cascaded mechanical systems. Its parameters are obtained by least-squares estimation as

$$
\begin{aligned}
A & =\left[\begin{array}{llll}
0 & 1 & 0 & 0 \\
0 & 0 & 1 & 0 \\
0 & 0 & 0 & 1 \\
-1.162 & -38.38 & -4.560 & -0.124
\end{array}\right] 10^{3} \\
B & =\left[\begin{array}{l}
-3.94 \\
487.89 \\
-427.01 \\
323.71
\end{array}\right] 10^{3}, \quad C=\left[\begin{array}{l}
1 \\
0 \\
0 \\
0
\end{array}\right]^{T} .
\end{aligned}
$$

In order to utilize the state-space model in the closed-loop control and get accurate model, the continuous-time input-output data is collected from the real-time system with closed-loop dynamics. The modeling results are very accurate. To focus on the extremum seeking control they are not illustrated here. The above state-space model will be used as the approximate model of the system.

In the extremum seeking controller/estimator design, the high-frequency modulation signal is first designed as a sine or cosine signal with a phase shift. However, the high-frequency modulation signal has a constant frequency and phase therefore it is a deterministic signal. The constant frequency phase sine signal drives the parameter change to find the minimum/ maximum of cost function in very small near local point. Therefore, it is very difficult to find a proper frequency and phase value with other design parameters. In literature, this problem is solved by using a white noise driven sine signal. Therefore, the modulation signal has infinite variable high frequency with stochastic behavior. In fact, this kind of modulation signal excites all dynamics of the cost function change, then the parameter change might get rid of the local minimum/maximum points. Therefore, in this work, the extremum seeking based controller and estimator are designed with stochastic modulation signal.

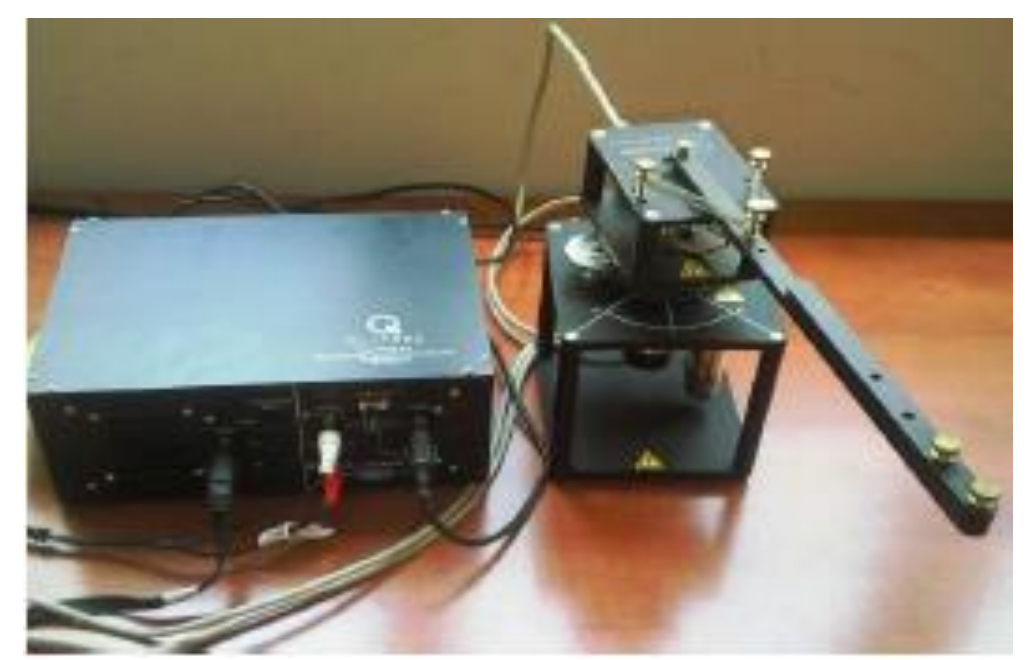

Figure 3. Experimental set-up for flexible-joint manipulator.

Let us summarize the proposed methods. The followings are achieved in control process.

- Using input-output data of the system, a state-space model is constructed. 
- Based on the state-space model, an extremum seeking controller is designed and applied to the real-time system.

- For disturbance and uncertainty case, an extremum seeking fault estimator is designed based on the state space model.

- Using the estimated fault with extremum seeking controller, a fault tolerant controller is designed. The estimated fault is used as an additional input of the system.

In this way, the fault tolerance can be performed without knowing the system model. In addition, the effect of unknown process faults and disturbances are compensated. Note that the fault estimator and controller have different designs. However, the filter parameters are designed same since the same experimental system is used. The gain of the integrator can be changed since in real-time in order to force the system to the desired dynamics. There is required relatively large gains in estimator design. The main difference comes from the objective functions. Controller minimizes the tracking error; estimator minimizes the estimation error.

The parameters of the estimator and controller can be found by using optimization methods, gridsearch, or trial-and-error approach. In this study, the filter cut off frequencies $w_{L}=1 \mathrm{rad} / \mathrm{sec}$ and $w_{H}=$ $100 \mathrm{rad} / \mathrm{sec}$ are initially designed both for extremum seeking estimator and controller. After that the gain constants $k$ and $a$ are tuned by a grid-search from a reasonable interval. Then, the most suitable parameters are found as $a=0.01$ and $k=450$ for the extremum seeking controller and $\alpha=0.01$ and $\beta=$ 1200 for the extremum seeking estimator, respectively. The designed fault tolerant controller is applied to the robot manipulator with same scenario both in numerical simulation and real-time application. The period is selected $T=100$ [seconds] where the sampling period is $T_{S}=2 \times 10^{-3}$ [seconds] with RungeKutta integration routine. The controller and fault-estimator begin the process instantaneously, then a large constant fault, that is in fact a handling a heavy payload, is applied to the system between 30th and 60th seconds.

\section{NUMERICAL SIMULATIONS}

In simulation study, we can apply the fault as an additional input of the state space model. Therefore, the fault estimator estimates the fault numerically exact value then its effect is compensated by the extremum seeking controller. In Figure 4 tracking results are shown. Figure 4(a) shows sine signal tracking, and the resulting tracking error is given in Figure 4(b). The main subject of the method is the applied control signal which is seen in Figure 4(c). The corresponding variation of the input signal which is the right before the integrator is presented in Figure 4(d).

In Figure 5 extremum seeking optimization-based estimation results are shown. Based on the estimated fault the difference between the estimated output and the system output are shown in Figure 5(a). The corresponding estimation error which is an extremum seeking optimization error is given in Figure 5(b). The estimated fault shown in Figure 5(c) is very accurate result. The effect of the fault signal is seen in the applied control signal. Due to the fault compensation its effect is very less on the tracking result. For the extremum seeking estimator, in order to excite all dynamics, the applied dither signal is illustrated in Figure 5(d). It is a white noise which has very aggressive change. Later, the deterministic and stochastic modulation-based fault tolerant control comparison will be given. In addition, the shape of the fault is not important the fault estimation error can converge to the zero very fast. The constant large value is applied since a large payload will be attached to the manipulator end-effector in real time. 


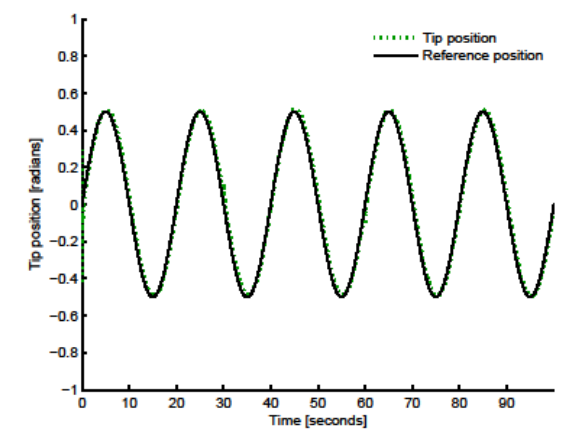

a) Reference tracking.

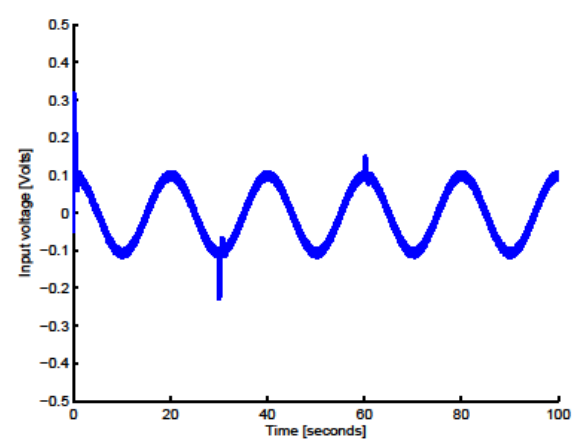

c) Control voltage.

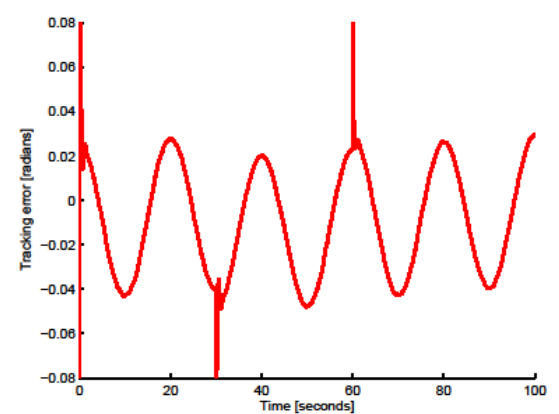

b) Tracking error.

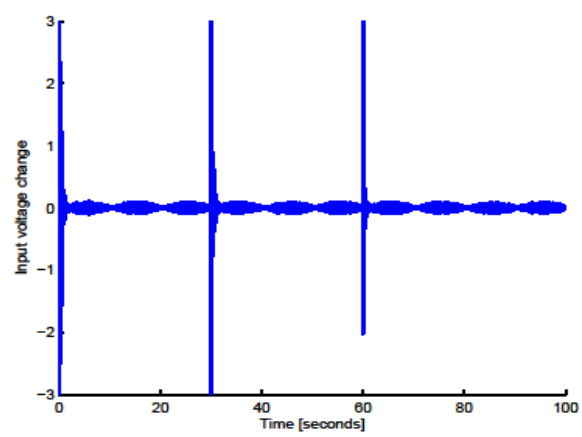

d) Variation of control voltage.

Figure 4. Simulation Study: ESC based fault tolerant control of manipulator. An artificial constant fault is applied between 30th and 60th seconds.

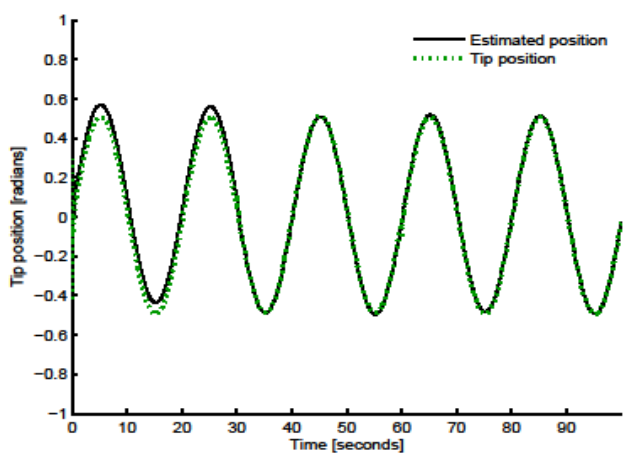

a) Output estimation.

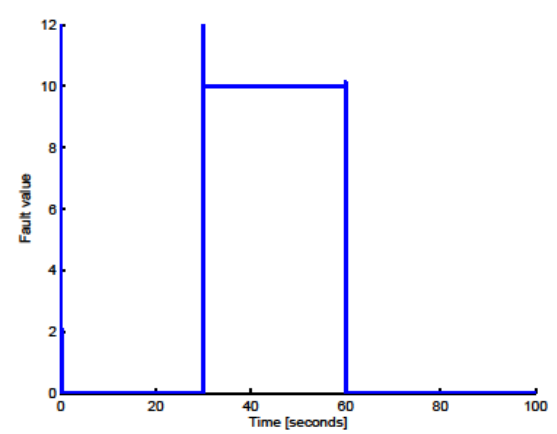

c) Fault estimation.

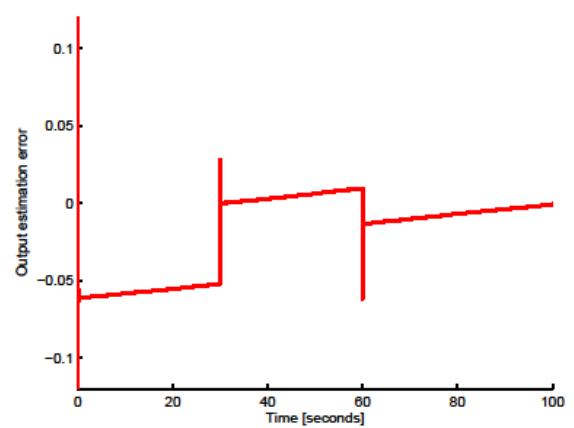

b) Estimation error.

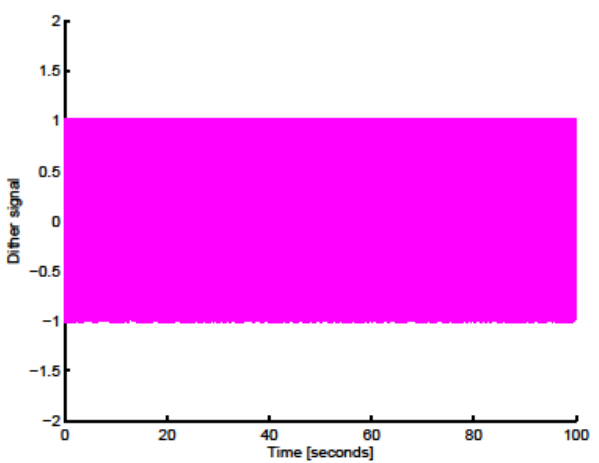

d) Applied dither signal.

Figure 5. Simulation Study: ESO based fault estimation results. An artificial constant fault is applied between 30th and 60th seconds. 
This result exhibits the main contribution of the proposed idea. As expectedly, the numerical simulation results are very accurate due to the well-defined dynamics without any noise or disturbance and the performance of the proposed fault tolerant controller.

\section{EXPERIMENTAL RESULTS}

In real-time experiments, we cannot introduce an additional input to the system except applied control voltage. Therefore, the effect of the time-varying payload will be compensated by the recovered input voltage. In other words, the fault tolerance is performed that the estimated fault is compensated by adding to the input voltage. In fact, this constraint brings an advantage of the proposed fault tolerant controller since there exist another fault such as unmodeled dynamics or noises. In the figures, the effect of unknown and estimated faults except additional payload can be observed. As the same scenario, an additional large payload is applied to the system between the 30th and 60th seconds.

Real-time control results are shown in Figure 6. The tip position of the end-effector and the reference signals are plotted in Figure 6(a). The corresponding tracking error is shown in Figure 6(b). The applied control signal and its variation which generated by the extremum seeking controller is presented in Figure 6(c) and Figure 6(d), respectively. Real-time extremum seeking based estimation results are illustrated in Figure 7. The system output tip position and estimated tip position are shown in Figure 7(a). The output estimation error which is between the approximate system model and the system output is plotted in in Figure 7(b). The estimated fault which decreases both the output estimation error and tracking error is given in Figure 7(c). Finally, the real-time applied high frequency in fact infinite frequency white noise signal is presented in Figure 7(d). In the application results, it is seen that there exists always a fault value which can be discrepancy between the system and approximate model. However, the effect of the applied additional payload fault is clearly seen in the dynamics. As explained above, by the fault compensation, the applied control signal varied between the 30th and 60th seconds.

Remember that the extremum seeking is not based on the system model, therefore the effect of the varying payload can be compensated by utilizing the sole extremum seeking controller. Therefore, the extremum seeking controller is applied to the system without fault compensation and the tracking error RMSE is given in Table 1. The advantage of the fault estimation and tolerance is effectively seen from the numerical results. 


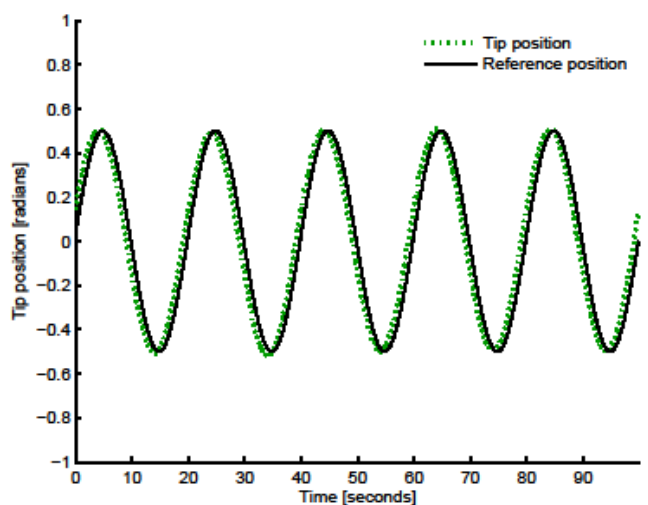

a) Reference tracking.

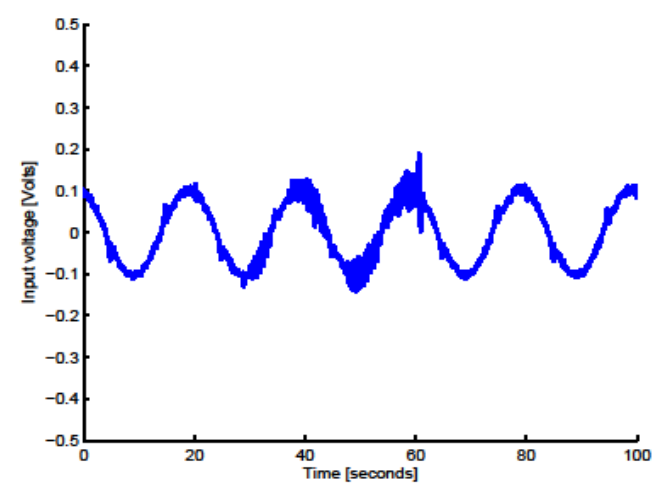

c) Control voltage.

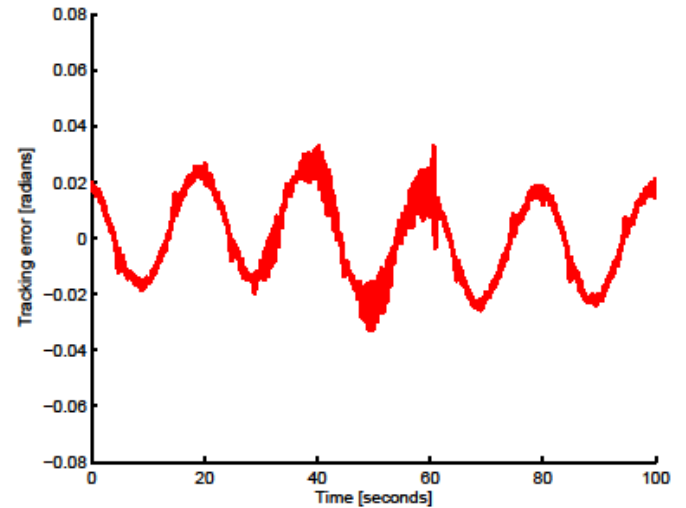

b) Tracking error.

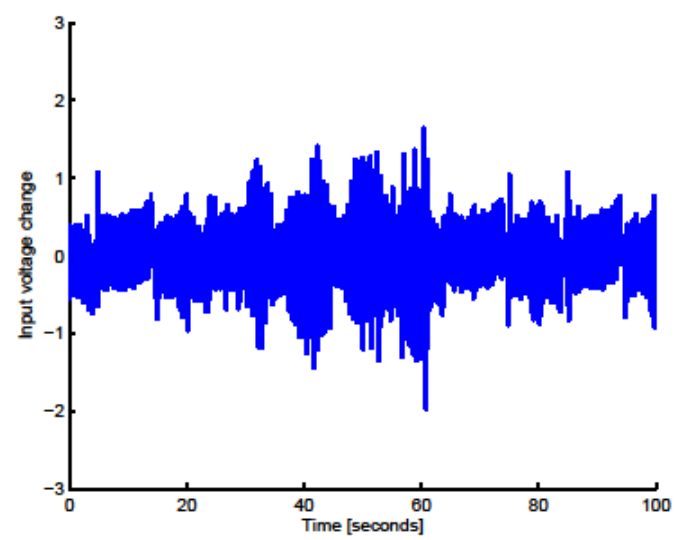

d)Variation of control voltage.

Figure 6. Experiment: ESC based fault tolerant control of manipulator. An additional payload is applied between 30th and 60th seconds.

Table 1. Performances of the real-time applications.

\begin{tabular}{l|c|c} 
Method/RMSE & Tracking & Estimation \\
\hline ESC without fault tolerance & 0.0373 & do not exist \\
\hline ESC with fault estimation & 0.0252 & 0.0223
\end{tabular}




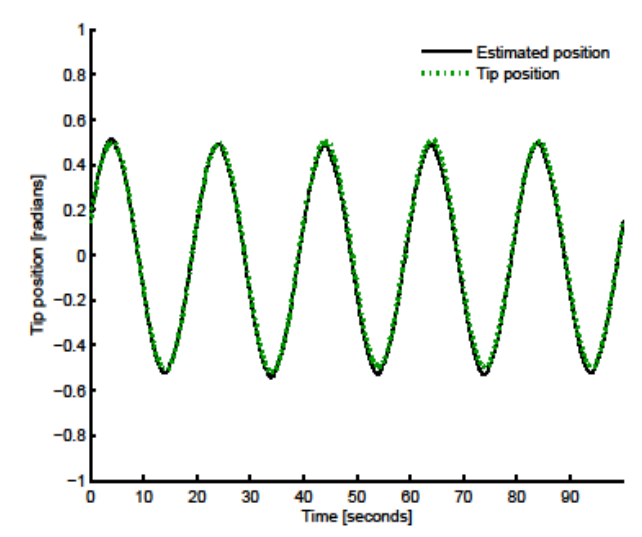

a) Output optimization.

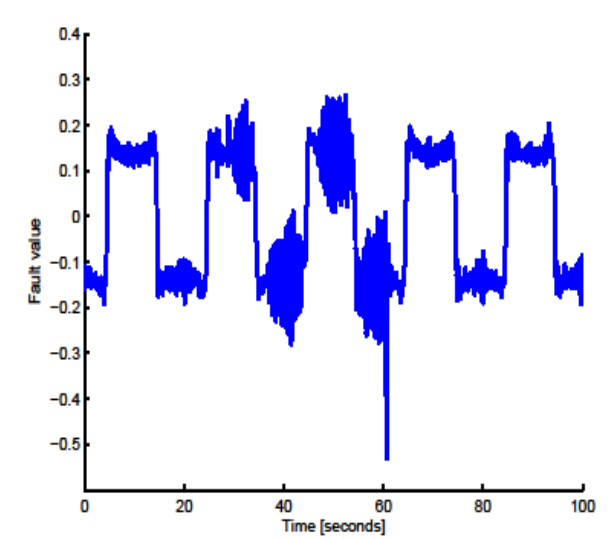

c) Adaptive fault estimation.

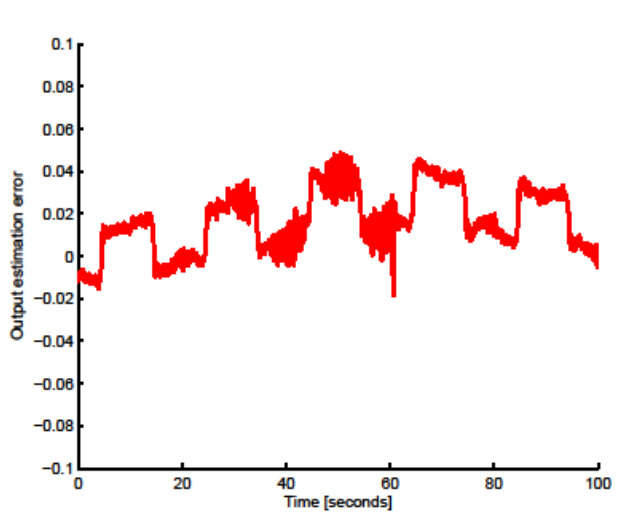

b) Optimization error

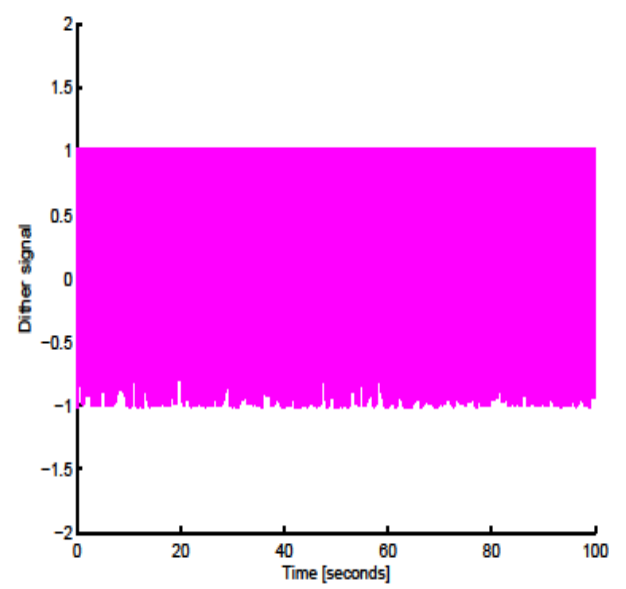

d) Applied dither signal.

Figure 7. Experiment: ESO based estimation results. An additional payload is applied between 30th and 60th seconds.

\section{CONCLUSION}

In this paper, extremum seeking based adaptive fault estimation and output feedback controller are designed and experiments are conducted on the experimental flexible joint manipulator. An unknown fault is adaptively estimated using extremum seeking optimization to minimize the estimation error between the real-system and an approximate model of the system. The advantage of the extremum seeking based fault estimation is to estimate the any fault in system dynamics that causes a change in system output. Then, using estimated fault in the closed-loop control, better tracking results are obtained. The designed fault tolerant controller can be successfully used for also highly nonlinear systems when an accurate system model exists. The accurate system model can be constructed using one of the successful system identification techniques since the controller and estimator are designed based on the system identification model. In general, for these kind of unknown systems with uncertainties are usually controlled using adaptive controllers. However, determination of initial parameters, tuning the parameters and parameter drift problems are main deficiencies of the adaptive control. For the proposed configuration, these are not the problems. But, the accuracy of the identification model and determination of the extremum seeking parameters are the main design problems. But in the control process, the designed fault estimation model estimates also the unmodeled dynamics of the system. Therefore, the estimation and control results based on the real-time experiments show the applicability of the proposed configuration. 


\section{REFERENCES}

Agee J. T., Z. Bingül, and S. Kizir, Tip trajectory control of a flexible link manipulator using an intelligent proportional integral controller," Transactions of the Institute of Measurement and Control, vol. 36, no. 5, pp.673-682, 2014.

Ariyur, K. B. and M. Krstic, Real Time Optimization by Extremum Seeking Control. New York, NY, USA: John Wiley \& Sons, Inc., 2003.

Astrom K. J. and B. Wittenmark, Adaptive Control, 2nd ed. Boston, MA, USA: Addison-Wesley Longman Publishing Co., Inc., 1994.

Beyhan S., Adaptive fuzzy terminal sliding-mode observer with experimental applications," International Journal of Fuzzy Systems, vol. 18, no. 4, pp. 585- 594, 2016.

Brunton S. L., C. W. Rowley, S. R. Kulkarni, and C. Clarkson, Maximum power point tracking for photovoltaic optimization using ripple-based extremum seeking control," IEEE Transactions on Power Electronics, vol. 25, no. 10, pp. 2531-2540, Oct 2010.

Chen S., L.Wang, K. Ma, and H. Zhao, A switching-based extremum seeking control scheme," International Journal of Control, vol. 0, no. 0, pp. 1-15, 2017.

Dochain D., M. Perrier, and M. Guay, Extremum seeking control and its application to process and reaction systems: A survey," Mathematics and Computers in Simulation, vol. 82, no. 3, pp. 369 380, 2011.

Dower P. M., P. M. Farrell, and D. Nesic, Extremum seeking control of cascaded raman optical amplifiers," IEEE Transactions on Control Systems Technology, vol. 16, no. 3, pp. 396\{407, May 2008.

Groves K. and A. Serrani, Modeling and nonlinear control of a single link exible joint manipulator, Ohio State Univ., 2004.

Guay M. and D. Dochain, A multi-objective extremum-seeking controller design technique," International Journal of Control, vol. 88, no. 1, pp. 38-53, 2015.

Guay M., D. Dochain, and M. Perrier, Adaptive extremum seeking control of continuous stirred tank bioreactors with unknown growth kinetics," Automatica, vol. 40, no. 5, pp. 881-888, 2004.

Hazeleger, Leroy, Mark Haring, and Nathan van de Wouw. "Extremum-seeking control for optimization of time-varying steady-state responses of nonlinear systems." Automatica 119 (2020): 109068.

Killingsworth N. J. and M. Krstic, PID tuning using extremum seeking: online, model-free performance optimization," IEEE Control Systems, vol. 26, no. 1, pp. 70-79, Feb 2006.

Krstic M. and H.-H. Wang, Stability of extremum seeking feedback for general nonlinear dynamic systems," Automatica, vol. 36, no. 4, pp. 595-601, 2000.

Lara G. -Cisneros, R. Femat, and D. Dochain, Robust sliding mode-based extremum-seeking controller for reaction systems via uncertainty estimation approach," International Journal of Robust and Nonlinear Control, 2017, dOI:10.1002/rnc.3736.

Liu S.-J. and M. Krstic, Stochastic Averaging and Stochastic Extremum Seeking. Springer London, 2012.

Noura H., D. Theilliol, J.-C. Ponsart, and A. Chamseddine, Fault-tolerant Control Systems: Design and Practical Applications, ser. Series: Advances in Industrial Control. Springer Dordrecht Heidelberg London New York, Aug.2009.

Oliveira T. R., A. J. Peixoto, and L. Hsu, Global real-time optimization by output-feedback extremumseeking control with sliding modes," Journal of the Franklin Institute, vol. 349, no. 4, pp. 1397 1415, 2012, special Issue on Optimal Sliding Mode Algorithms for Dynamic Systems.

Pan Y., U. Ozguner, and T. Acarman, Stability and performance improvement of extremum seeking control with sliding mode," International Journal of Control, vol. 76, no. 9-10, pp. 968-985, 2003.

Quanser Inc., Canada, Rotary Flexible Joint User Manual, 2012.

Sassano M., D. Carnevale, and A. Astol, Extremum seeking-like observer for nonlinear systems," IFAC Proceedings Volumes, vol. 44, no. 1, pp. 1849-1854, 2011.

Spooner J., M. Maggiero, R. Ordonez, and K. M. Passino, Stable Adaptive Control and Estimation for Nonlinear Systems: Neural and Fuzzy Approximator Techniques. John Wiley \& Sons, 2002. 
Subbaraman A. and M. Benosman, Extremum seeking-based iterative learning model predictive control" IFAC-Papers OnLine, vol. 49, no. 13, pp. 193-198, 2016.

Talole S. E., J. P. Kolhe, and S. B. Phadke, Extended-state-observer based control of flexible-joint system with experimental validation," IEEE Transactions on Industrial Electronics, vol. 57, no. 4, pp. 1411\{1419, April 2010.

Tan Y., D. Nesic, I. Mareels, and A. Astol, On global extremum seeking in the presence of local extrema," Automatica, vol. 45, no. 1, pp. $245-251,2009$.

Ye M. and G. Hu, A robust extremum seeking scheme for dynamic systems with uncertainties and disturbances," Automatica, vol. 66, no. C, pp. 172-178, Apr. 2016.

Zhang C. and R. Ordonez, Numerical optimization-based extremum seeking control with application to abs design," IEEE Transactions on Automatic Control, vol. 52, no. 3, pp. 454-467, March 2007.

Zhao, Zhongfan, et al. "Local self-optimizing control based on extremum seeking control." Control Engineering Practice 99 (2020): 104394. 